\title{
FRICTIONAL POWER LOSSES ON SPUR GEARS WITH TIP RELIEFS. THE LOAD SHARING ROLE
}

\author{
A. Diez-Ibarbia, A. Fernandez-del-Rincon, A. de-Juan, \\ M. Iglesias, P. Garcia, F. Viadero \\ Department of Structural and Mechanical Engineering, University of Cantabria. Avda. \\ de los Castros s/n 39005 Santander, Spain.
}

\begin{abstract}
The load sharing impact on the efficiency of spur gears with modified profile was assessed in this work. The aim was to analyse the influence of the profile modifications on the load sharing, which also considers the effect of the torque level on the system deflections, and how these load sharing variations affected the system efficiency. Due to the frictional effect importance on power losses, in the operating conditions considered, sliding friction between teeth in presence of lubricant was studied in this proposal. The results established that tip relief improves the efficiency of the system due to the reduction of effective contact ratio. Moreover, there is a tip relief which makes optimal the efficiency in specific operating conditions, corresponding to the unit value of the effective contact ratio. Thus, the main conclusion of this work is that the tip relief which makes optimal the efficiency coincides with the theoretical dynamic optimum of the transmission.
\end{abstract}

Keywords: Efficiency, Power losses, Load sharing, Profile modifications, Tip relief

\section{Introduction}

Mechanical transmissions are widely used in every kind of industrial applications as the mechanism which transfers the power from the input element, which generates the energy, to the receiver. One of the most utilised transmissions is the one that uses gears as transmitter of energy. This kind of transmission is very common due to its robustness, reliability and compactness. However, a characteristic that defines them and has made them 
prevail over other kinds of transmissions, it is their high efficiency in the most adverse operating conditions.

The analysis of efficiency in gear transmissions, as a fundamental element of powertrains, is an interesting aspect on which the research community has focused their efforts $[1,17,23,31,26,33]$. In this regard, there is a need to use increasingly efficient transmissions, not only because of the inherent reduction of energy consumption and therefore of operating costs, but also to meet the more and more restrictive environmental requirements, for instance in vehicles [28]. Environmental policies have made it mandatory to reduce the level of emissions as well as the adjustment of the fuel economy. Although these two reasons are sufficient for researching in this field, there are other reasons to improve this aspect in parallel. It is logical to think that the more efficient a transmission is, the less heat it will dissipate, and therefore, the lower its operating temperature will be. All of this will turn into a lower probability of causing superficial fatigue and wear in teeth or a premature failure of the gear. Hence, increasing the system efficiency will not only result in a reduction of operating and maintenance costs in the short term, but also in the medium and long term, by means of reducing associated breakdowns.

Although in these transmissions there are more elements than the gears themselves, such us bearings, seals and other auxiliary elements, this work is only focused on gears, being the most influential element of the system in terms of power losses in the considered operating conditions (considerable loads) $[1,8,31]$. The power losses in gear elements are usually distinguished into two types; those that depend on the load and those that do not. Loaddependent power losses are usually divided into those due to sliding friction and those corresponding to the rolling friction, depending on the relative movement between the surfaces of the teeth. Non-load-dependent power losses are those due to fluid motion in the transmission surroundings, which could be lubricating fluid, air or both of them. In the work operating conditions, sliding friction is the dissipative effect that causes the most of power losses, as it can produce up to $95 \%$ of the system power losses under adverse conditions of load $[1,31]$. Thus, it is generally assumed that sliding friction is the only dissipative effect of the system [2, 13, 29, 32, 33].

The main goal of the present study is to determine the influence of the load sharing on the efficiency of spur gear transmissions when different tip reliefs are considered. Tip relief is widely used in the Industry in order to improve the dynamic behaviour of the transmission by softening the transition between the double and the single contact regions. To consider its behaviour 
in the numerical model of gear transmissions, it is necessary to take into account the deflections produced by the adjacent teeth to the one in contact, in other words, the effect of the torque level. In this framework, the strength of the present proposal lies in the use of an enhanced load sharing formulation, which considers the profile modifications and the torque level, in the efficiency calculation. There are several works which analyse the tip relief influence on the dynamic properties of gear transmissions [5, 12, 14, 15, 18, 19, 20] and on the tooth stress produced $[16,22,30]$. Nevertheless, in the efficiency field, it only exists few works $[4,6,21,33]$. Some of them are based on the experimental calculation of the power losses in gear transmissions with short and long tip reliefs $[6,21]$, other works use numerical models which do not generally take into account the torque effect in order to calculate the system power losses [4] and others which propose analytical solutions of the efficiency considering the tip relief effect, comparing the results with numerical simulations [33]. Hence, with this proposal, it is intended to contribute to improve the knowledge in this regard, using a load contact model which does take into account the torque level and allows for calculating efficiency values with a high level of accuracy.

In Section 2, the fundamentals that were required to develop the efficiency study are shown. Section 3 provides the analysed transmission properties and the structure of the results presented in Section 4 and 5. To end this work, the conclusions are summarized in Section 6.

\section{Fundamentals applied to this study}

Two aspects are necessary to be defined in order to comprehend the scope of this study. Since the assessment of the efficiency of gear transmissions with tip relief was performed, the efficiency calculation methodology and the model to include tip reliefs are presented next.

\subsection{Efficiency calculation}

The methodology to calculate the efficiency has been presented in previous works [7]. Accordingly, in this section, only a few details, which are necessary for the understanding of the work, are presented for the sake of simplicity.

As the Coulomb's model approach was followed to calculate the sliding friction, hereinafter referred as friction, power losses $\left(P_{\text {loss }}\right)$ along the mesh 
cycle are dependent of the sliding velocity $\left(V_{s}(\theta)\right)$, the friction coefficient $(\mu(\theta))$ and the contact force $\left(F_{N}(\theta)\right)$ :

$$
\begin{gathered}
P_{\text {loss }}=\int_{\theta_{A}}^{\theta_{E}} \mu(\theta) F_{N}(\theta) V_{s}(\theta) d \theta=P_{\text {in }} \int_{\theta_{A}}^{\theta_{E}} I P L d \theta \\
\Rightarrow I P L=\frac{\mu(\theta) F_{N}(\theta) V_{s}(\theta)}{F_{N \max } V}
\end{gathered}
$$

Where $F_{N \max }$ is the maximum normal force, $V$ the pitch line velocity along the mesh cycle and IPL the Instantaneous Power Loss factor. Moreover, $\theta_{A}$ and $\theta_{E}$ correspond to the angular positions at the mesh cycle beginning and end.

In this proposal, in order to calculate the friction coefficient, a constant average formulation was implemented $\left(\mu_{m}\right)$. The reason why this assumption was included is to isolate the effect of the load sharing in the efficiency from the impact of the friction coefficient. Moreover, Niemann's proposal (equation 1 ) is the chosen formulation since it is widely used in the scientific literature $[2,8,13,24,25,29]$. This formulation depends on the contact force, the speed, the geometry of the transmission and the rheological parameters.

$$
\begin{gathered}
\mu_{m}=0.048\left(\frac{\frac{F_{\text {Nmax }}}{b}}{V_{\Sigma C} \rho_{c}}\right)^{0.2} \eta_{\text {oil }}^{-0.05} R_{a}^{0.25} X_{L} \\
\Rightarrow V_{\Sigma C}=2 V_{t} \sin (\varphi) \quad \text { and } \quad X_{L}=\frac{1}{\left(\frac{F_{\text {Nmax }}}{b}\right)^{0.0651}}
\end{gathered}
$$

Where $\rho_{c}$ is the equivalent curvature radius in the pitch point, $b$ the gear width and $R_{a}$ the mean roughness of the teeth profile.

In order to obtain the load sharing $\left(\frac{F_{N}(\theta)}{F_{N \max }}\right)$, the Load Contact Model $(L C M)$ previously developed by the authors was used. This $L C M$ superposes two models with different scopes to determine the deflections; a finite element model to calculate global deformations and a Hertzian formulation to obtain the local deflections $[9,10,11]$. This approach allows for considering the deflections of the adjacent teeth of those in contact, achieving in this manner to take into account the effect of using different torque levels. Furthermore, one of the features developed in this $L C M$ is the profile modifications formulation, specifically, in this work, gear transmissions with tip reliefs are to be assessed. For this reason, the model utilised to include their behavior is presented next. 


\subsection{Profile modifications formulation}

As commented, profile modifications are widely used in the Industry in order to improve the dynamic behaviour of the transmission, but its effect on the efficiency still needs to be assessed in deep. In this section, the formulation used to implement them in the $L C M$ is presented (Figure 1).

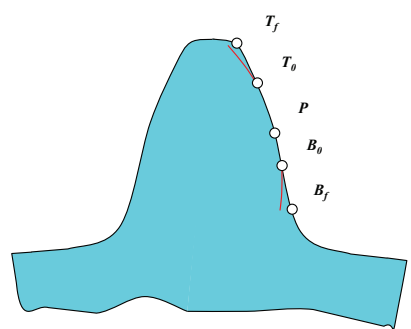

$$
\begin{aligned}
& e_{T}(s)=C_{T}\left(\frac{\left(s-s_{T_{0}}\right)}{\Delta L_{T}}\right)^{n} \\
& n=1,2 ; \quad s \in\left[s_{T_{0}}, s_{T_{f}}\right]
\end{aligned}
$$

Figure 1: Formulation of the profile modifications

$e_{T}(s)$ represents the length, which is measured in the line of action, of the tip relief, in other words, the gap included to the tooth. Subscript " $T$ " means that the profile modification is in the tooth tip, being the same model when bottom relief is included (subscript " $B "$ ). Moreover, the formulation allows to include a linear profile modification $(n=1)$ or a parabolic one $(n=2)$, which are the most common profile modifications in gear transmission field $[5,12,14,15,18,19,20]$. In this work, only linear profile modifications were considered, since the load sharing is almost unaffected by this aspect in the operating conditions of the analysis [18].

Depending on the load applied to the transmission, two different tip reliefs are usually included to improve the dynamic behaviour of the system, long and short tip reliefs. The former are generally incorporated to transmissions which transmit high loads, whilst the latter are implemented in low-loaded transmissions. Long tip reliefs are those which make the theoretical contact ratio lower than the unity, being short tip reliefs in the contrary case [3, 27]. A priori, a transmission with a theoretical contact ratio lower than the unity is not desirable from the dynamic point of view, since impacts are foreseen. Nevertheless, in reality, since the deflections in transmissions which transmit high torque levels are considerable, with the proper tip relief, the effective contact ratio is equal to one and therefore, the mesh stiffness is almost uniform.

In this work, both kinds of tip relief are considered, for this reason, their nomenclature and definition are presented in Figure 2. 


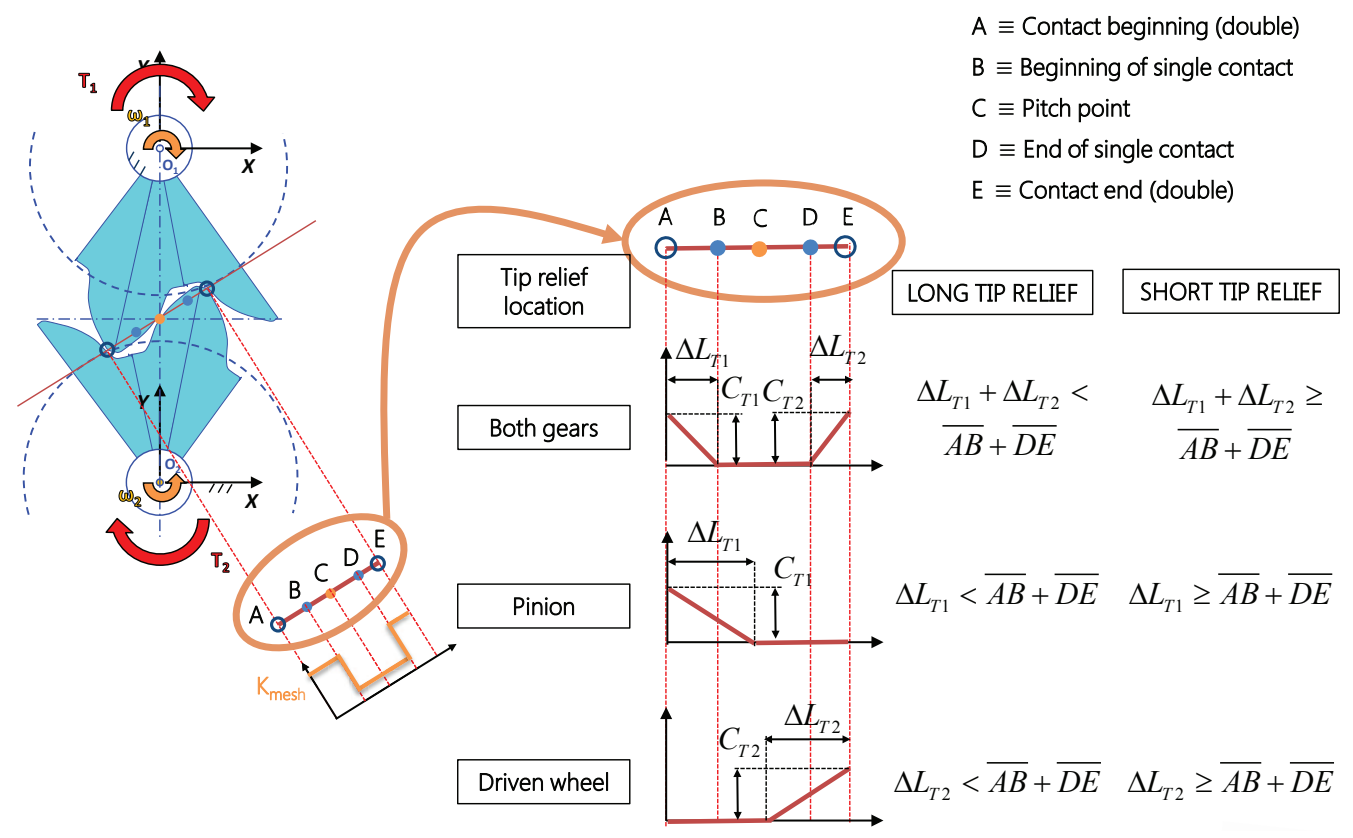

Figure 2: Layout of the tip relief case studies considered

\section{Case of application}

An efficiency assessment was performed to a spur gear transmission, which properties are specified in Table 1.

Table 1: Pinion/gear parameters

\begin{tabular}{|cc|cc}
\hline \multicolumn{4}{c}{ Main parameters } \\
\hline Number of pinion teeth & 18 & Module & 3 \\
Number of gear teeth & 36 & Pressure angle & $20^{\circ}$ \\
Mean Roughness & $0.8 \mu \mathrm{m}$ & Face width & $26.7 \mathrm{~mm}$ \\
\hline
\end{tabular}

Two different studies were done to this standard transmission. The first consist of analysing the effect of different tip reliefs, which can be long and short, under two specific levels of torque (low and high). In Table 2, it can be appreciated the tip relief range assessed and the operating conditions of the transmission.

In the second study, the transmission with a specific tip relief (the longest considered in first study) is analysed under different levels of torque. In Table 3 , the torque range studied is shown as well as the tip relief specifications. 
Table 2: Operating conditions of the transmission and tip relief parameter range of the first study

\begin{tabular}{cccc||cc}
\hline Operating & Power & Torque & Speed & \multicolumn{2}{c}{ Tip relief $(\mathbf{m m})$} \\
\cline { 5 - 6 } conditions & $(\mathbf{k W})$ & $(\mathbf{N m})$ & $(\mathbf{r p m})$ & Length & Magnitude \\
\hline OC1 & 25 & 40 & 6000 & $1 \div 3$ & $0.01 \div 0.1$ \\
OC2 & 100 & 637 & 1500 & & \\
\hline
\end{tabular}

Table 3: Operating conditions of the transmission and tip relief parameters of the torque analysis

\begin{tabular}{ccc||cc}
\hline \multicolumn{3}{c||}{ Operating conditions } & \multicolumn{2}{c}{ Tip relief $(\mathbf{m m})$} \\
\hline Power $(\mathrm{kW})$ & Torque $(\mathbf{N m})$ & Speed $(\mathbf{r p m})$ & Length & Magnitude \\
\hline $6 \div 250$ & $20 \div 795$ & 3000 & 3 & 0.1 \\
\hline
\end{tabular}

\section{Study I: Profile modifications assessment}

In order to assess the influence of the tip relief in the efficiency, three cases of study, which are summarised in Figure 3 and Table 4, were set out. In the first, the efficiency was calculated when the tip reliefs were included in the pinion. In the second, the driven wheel has its profile modified, whilst in the third, both gears were considered to have the same tip reliefs.
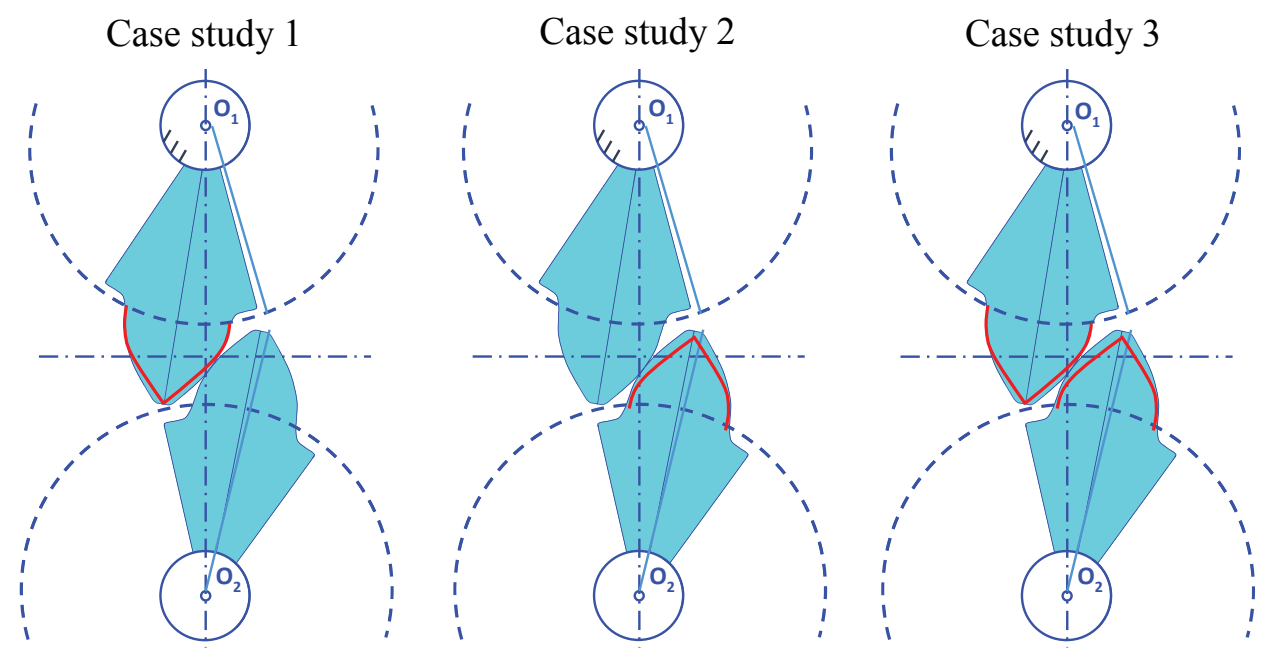

Figure 3: Layout of the tip relief case studies considered 
Table 4: Case studies description summary

\begin{tabular}{ccc}
\hline $\begin{array}{c}\text { Case study } \\
\text { Number }\end{array}$ & $\begin{array}{c}\text { Pinion tip } \\
\text { relief }\end{array}$ & $\begin{array}{c}\text { Driven wheel } \\
\text { tip relief }\end{array}$ \\
\hline 1 & Yes & No \\
2 & No & Yes \\
3 & Yes & Yes \\
\hline
\end{tabular}

These three case studies are justified since the efficiency was to be obtained when tip relief was included in the pinion, the driven wheel and in both gears, allowing for isolating the assessment of each kind of tip relief. Moreover, these tip relief ranges were chosen in order to analyse short and long tip reliefs. As short tip relief are implemented in the first and second case studies, the interest lies in the analysis of operating conditions with low levels of torque $(O C 1)$. Nonetheless, in the third case of study, both short and long tip reliefs are included, being of interest low and high torque levels $(O C 1$ and $O C 2)$. In this manner, the two operating conditions, which were shown in Table 2, were selected.

\subsection{First case study: Tip relief in the pinion}

In Figure 4, the efficiency values are shown for several pinion tip reliefs and the two considered operating conditions.

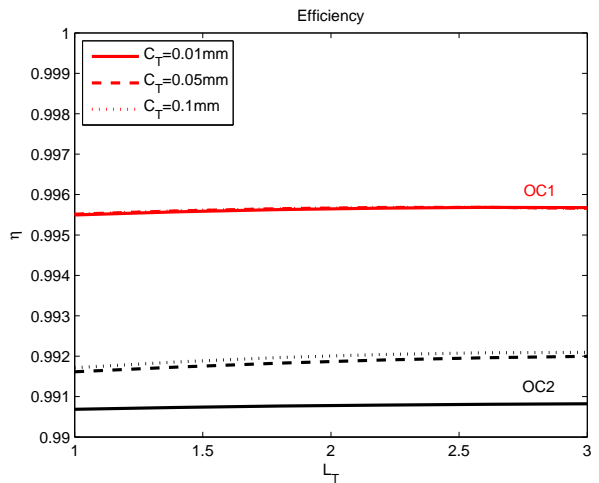

(a) Tip relief magnitude variation

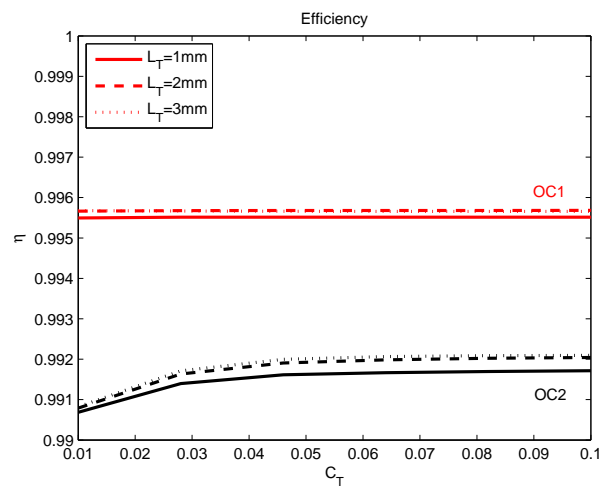

(b) Tip relief longitude variation

Figure 4: Efficiency values for several pinion tip reliefs and operating conditions $O C 1$ (in red) and $O C 2$ (in black) 
From Figure 4, the efficiency increases with the tip relief length in both operating conditions, whilst the magnitude increment of the tip relief only affects $O C 2$. Specifically, in the high-torque level case, there is a magnitude from which the efficiency becomes almost constant $\left(C_{T}=0.05 \mathrm{~mm}\right)$. This means that the deflections, which are produced by the high torque applied to the transmission, make that the contact in the tip relief profile exists until this magnitude value. With high tip relief magnitudes, only involute contact exists and therefore the length of the tip relief is the only parameter which affects the load sharing.

This trend can be explained by the parameters which affect the efficiency. For this reason, in Figure 5 and Figure 6 the load sharing $(L S)$, the friction coefficient $(F C)$ and the instantaneous power loss $(I P L)$ factor are presented for the minimum and maximum case of tip relief magnitude.

From Figure 5 and Figure 6, the introduction of pinion tip reliefs turns into a reduction of the First Double-Contact Region $(F D C R)$ and an increment of the Single-Contact Region $(S C R)$ after the pitch point. This fact results in a contact length reduction, which is higher with the tip relief length increment, starting the contact later.

For the minimum magnitude case, this effect is only appreciated in the low-torque case (in dash red line), whilst in the high-torque level case (in solid black line), there is a slight change of the load sharing in these regions, smoothing the transitions between Double-Contact-Regions $(D C R)$ and $S C R$. These facts have an influence on the load sharing and therefore on the power losses. Specifically, in the low-torque level case, there is a reduction of the power losses at the contact beginning ( $F D C R$ ), which is slightly higher than the increment of the power losses in the $S C R$. This turns into a small improvement of the efficiency. Nevertheless, in the high-level case, only there is a power loss reduction at the contact beginning due to the load sharing variation. This results in a higher improvement of the efficiency than in the low-torque level case.

For the maximum magnitude case, the contact reduction is appreciated in both operating conditions, following a similar pattern as in the low-torque level and minimum magnitude case. In other words, when the length of the tip relief increases, there is a power loss reduction in the $F D C R$, which is higher than the power loss increment in the $S C R$. This turns into a slight improvement of the efficiency. 

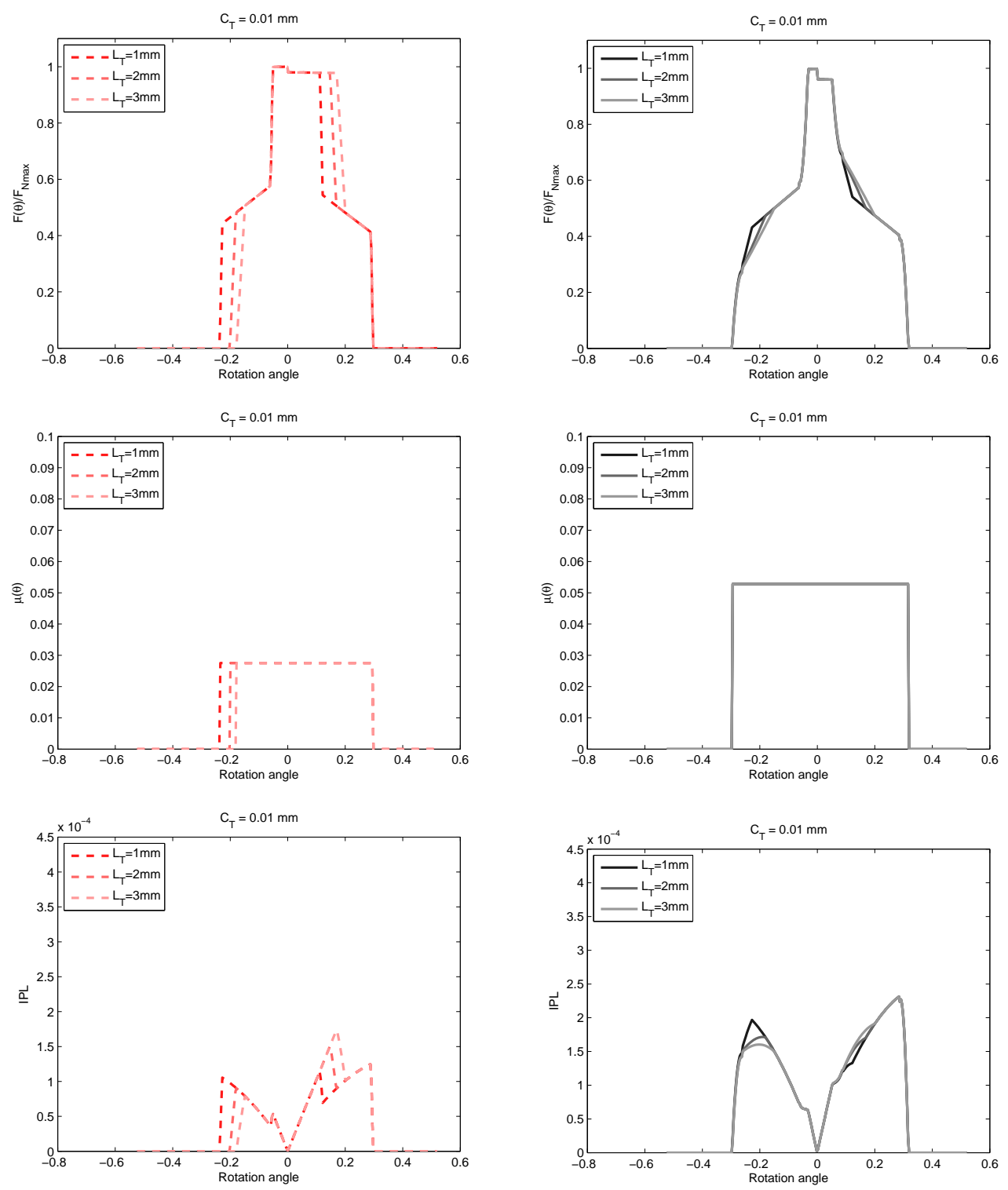

Figure 5: Effect of the tip relief length variation, in the minimum magnitude case, on $L S$, $F C$ and $I P L$ factor 

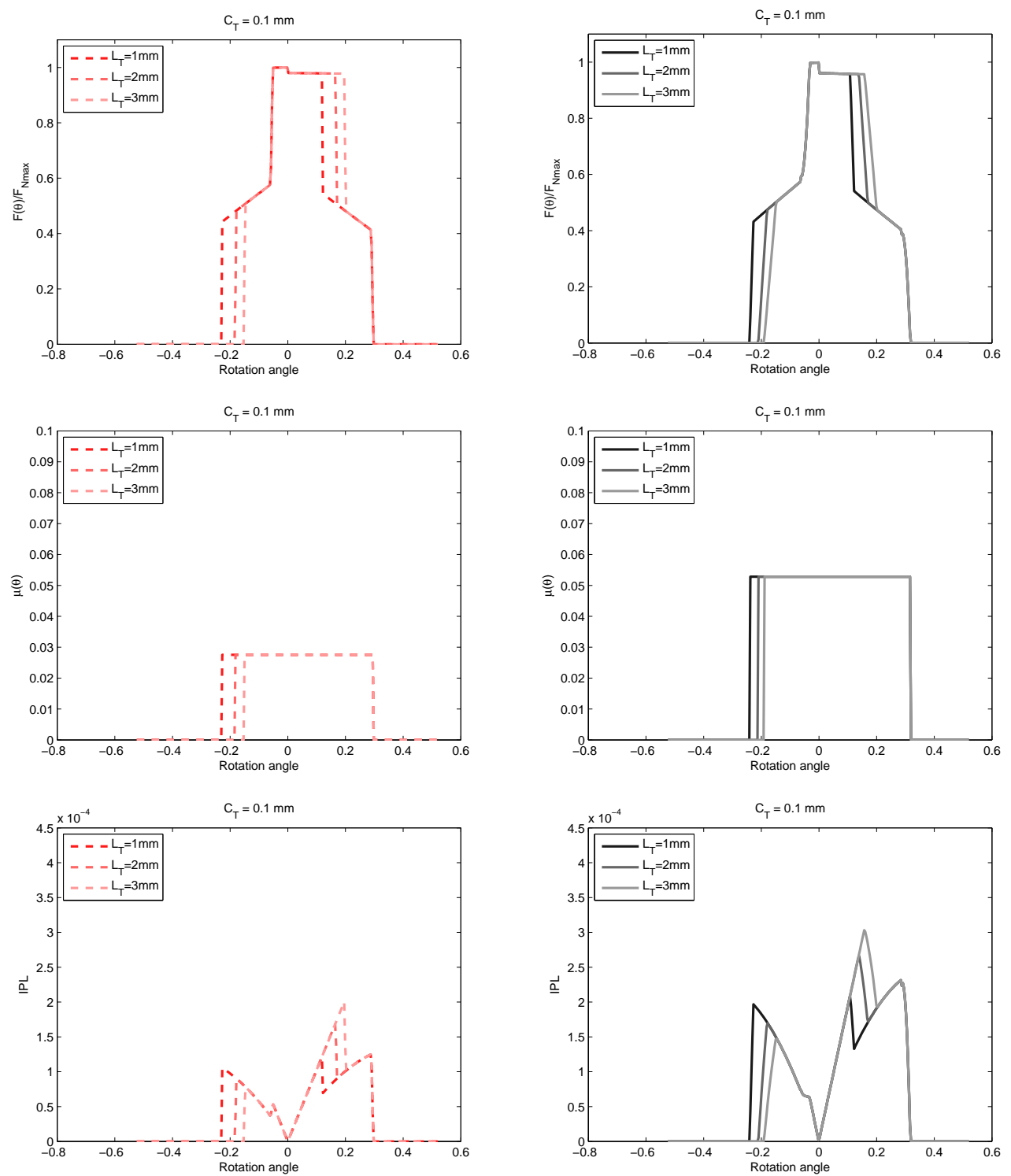

Figure 6: Effect of the tip relief length variation, in the maximum magnitude case, on $L S$, $F C$ and $I P L$ factor 


\subsection{Second case study: Tip relief in the driven wheel}

The efficiency values for several driven wheel tip reliefs are presented in Figure 7.

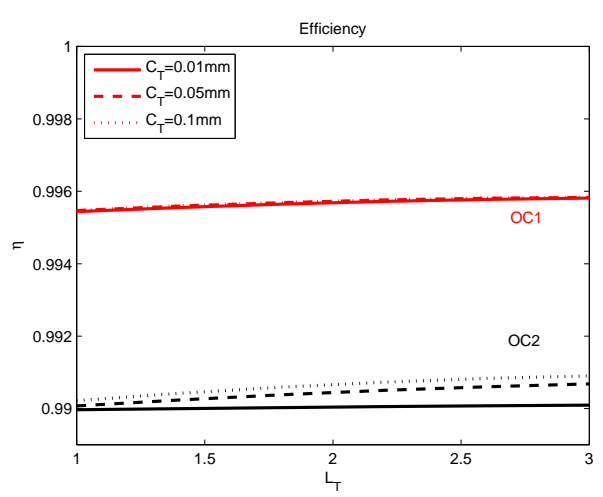

(a) Tip relief magnitude variation

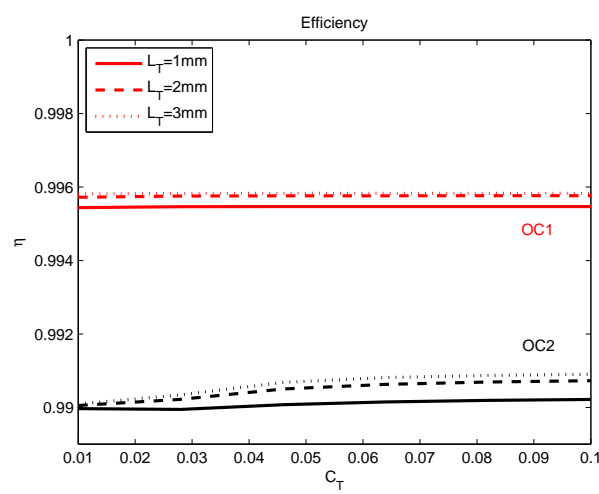

(b) Tip relief longitude variation

Figure 7: Efficiency values for several driven wheel tip reliefs and operating conditions

Figure 7 shows that the efficiency increases with the tip relief length in both operating conditions, whilst the magnitude increment of the tip relief only affects $O C 2$, following the same tendency as in first case study. In the high-torque level case, there is a magnitude from which the efficiency becomes almost constant $\left(C_{T}=0.05 \mathrm{~mm}\right)$.

In Figure 8 and Figure 9, the parameters which affect the efficiency are presented ( $L S, F C$ and $I P L$ factor) for the minimum and maximum case of tip relief magnitude, in order to analyse the efficiency trend.

The tip relief inclusion in the driven wheel produces a reduction of the Second Double-Contact Region $(S D C R)$ and an increment of the SingleContact Region $(S C R)$ before the pitch point. This fact results also in an overall contact length reduction, finishing the contact before with the tip relief length increment.

For the minimum magnitude case, this effect is only appreciated in the low-torque case, whilst in the high-torque level case, there is a slight change of the load sharing in these regions, smoothing the transitions between $D C R \mathrm{~s}$ and $S C R$. This affects the load sharing and therefore the power losses. In the low-torque level case, there is a power loss reduction of the at the contact end $(F D C R)$, which is higher than the power loss increment in the $S C R$, 
turning into a slight improvement of the efficiency. Nonetheless, in the highlevel case, it only exists a power loss reduction at the contact end because of the load sharing variation, improving the efficiency more than in the lowtorque level case.
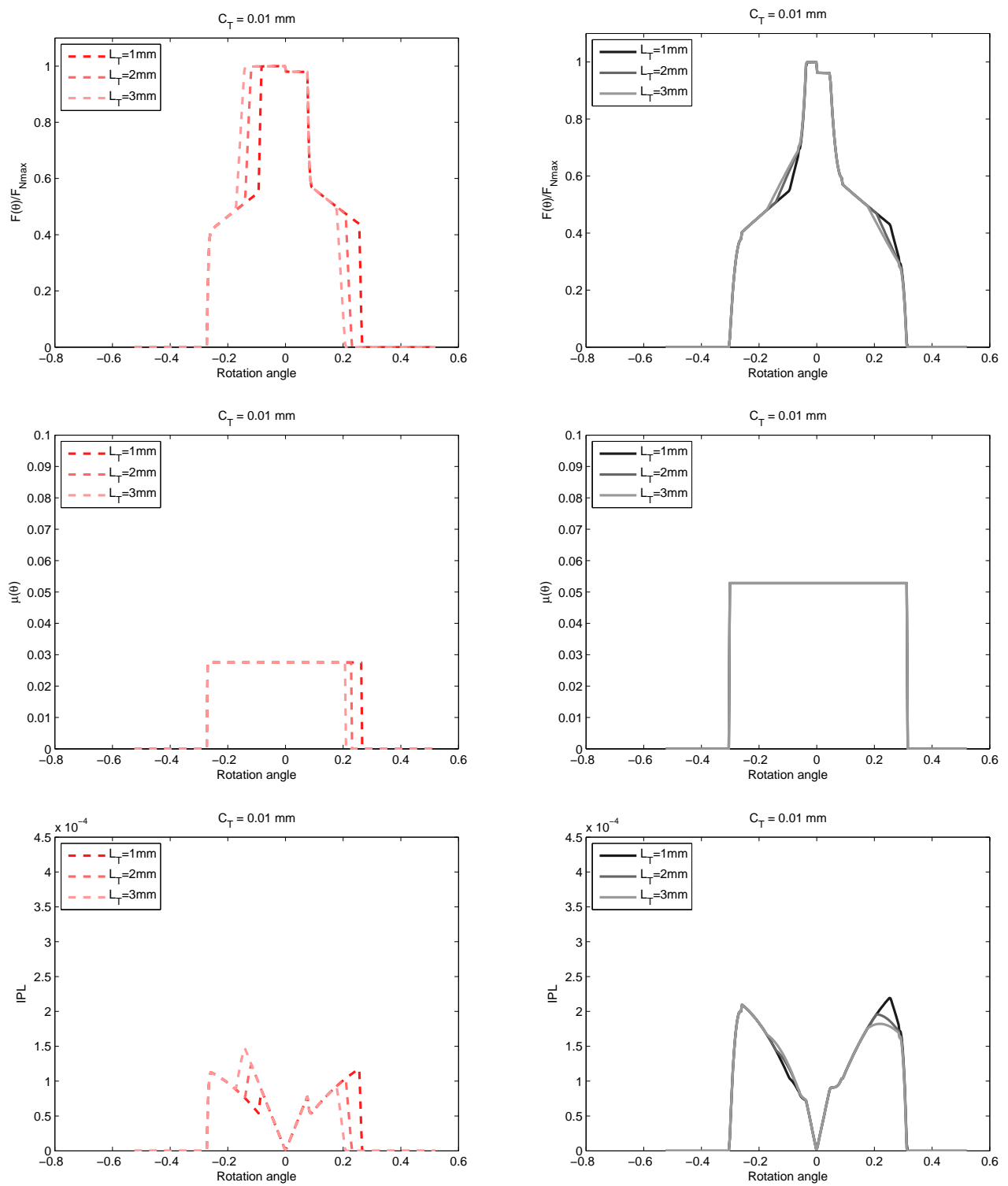

Figure 8: Effect of the tip relief length variation, in the minimum magnitude case, on $L S$, $F C$ and $I P L$ factor 

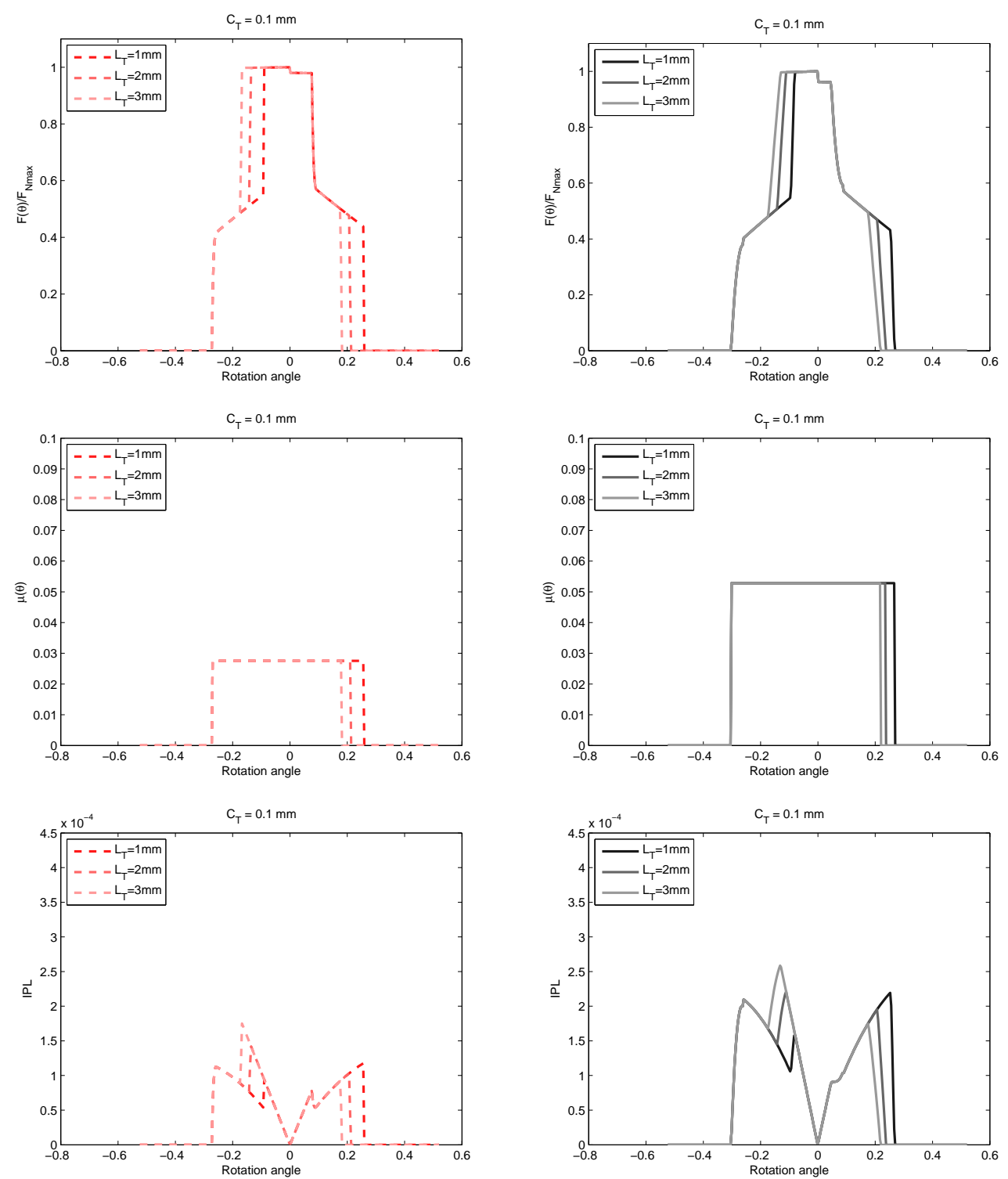

Figure 9: Effect of the tip relief length variation, in the maximum magnitude case, on $L S$, $F C$ and $I P L$ factor

In the maximum magnitude case, the contact reduction is appreciated in both operating conditions when the length of the tip relief increases. This results in a power loss decrement in the $S D C R$, which is higher than the power loss increment in the $S C R$, achieving a slight efficiency improvement. 


\subsection{Third case study: Tip relief in both gears}

In Figure 10, the efficiency values are shown when several tip reliefs were included in both gears. The study was constraint to implement the same tip relief to both gears.

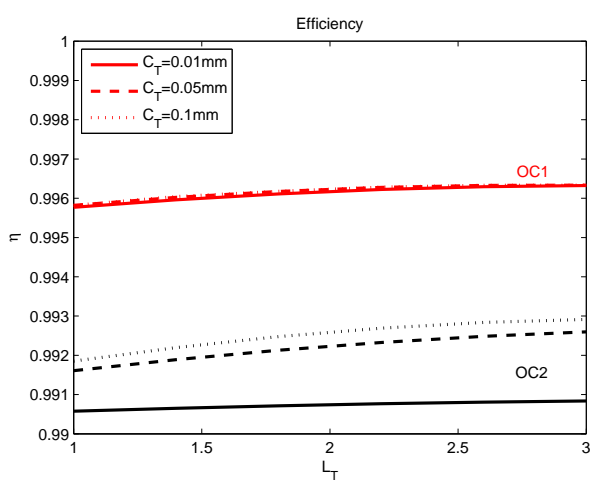

(a) Tip relief magnitude variation

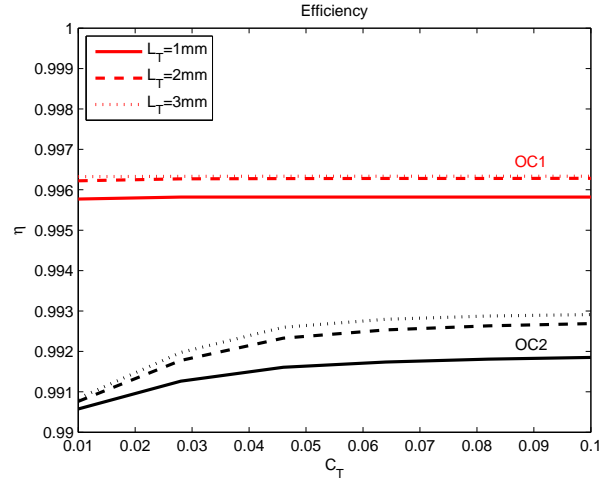

(b) Tip relief longitude variation

Figure 10: Efficiency values for several tip reliefs in both gears and operating conditions

From Figure 10, the efficiency increases with the tip relief length in both operating conditions, whilst the magnitude increment of the tip relief only affects $O C 2$. Comparing with the other two case studies, the efficiency increases more when tip reliefs are considered in both gears than when included in just one.

In Figure 11 and Figure 12, the parameters which affect the efficiency are presented ( $L S, F C$ and $I P L$ factor) for the minimum and maximum case of tip relief magnitude, in order to assess the appreciated efficiency tendency.

The effects observed in both previous cases of study are superposed in the current one. This means that the tip relief inclusion in both wheels produces a reduction of both $D C R \mathrm{~s}$ and an increment of the $S C R$ in both directions of the pitch point. This fact turns into an overall contact length reduction, thus, with the tip relief length increment, the contact starts after and finishes before.

For the minimum magnitude case, this effect is only appreciated in the low-torque case, since in the high-torque level case, there is no change of the contact ratio but a slight variation of the load sharing, smoothing the transitions between $D C R \mathrm{~s}$ and $S C R$. These facts are appreciated in the 
load sharing and in the power losses. In the low-torque level case, there is a power loss decrement at the contact beginning and end, which is higher than the power loss increment in the $S C R$. In the high-level case, there is only a
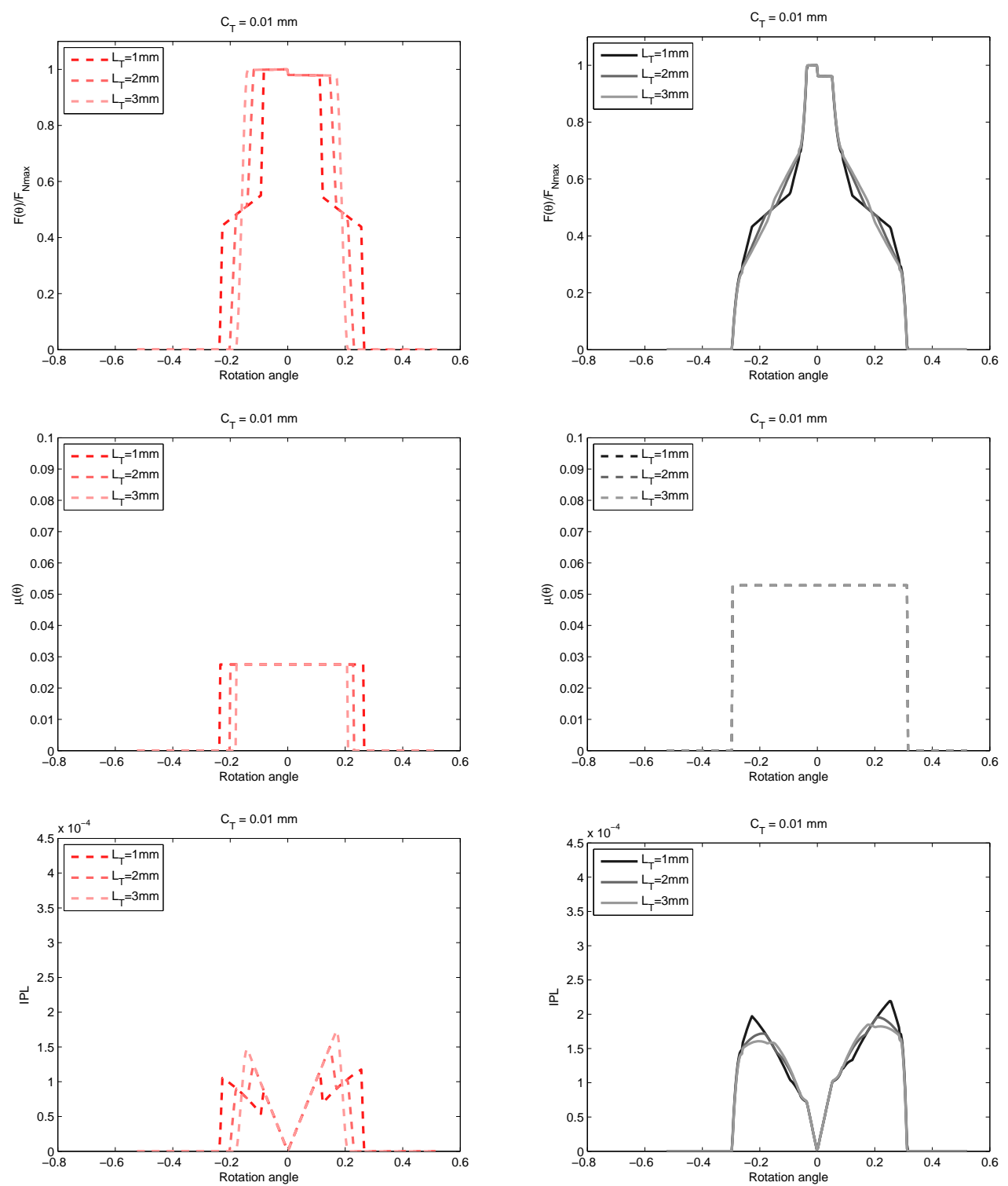

Figure 11: Effect of the tip relief length variation, in the minimum magnitude case, on $L S, F C$ and $I P L$ factor 
power loss reduction in these both regions because of the load sharing change (no power loss increment in $S C R \mathrm{~s}$ ), improving the efficiency more than in the low-torque level case.
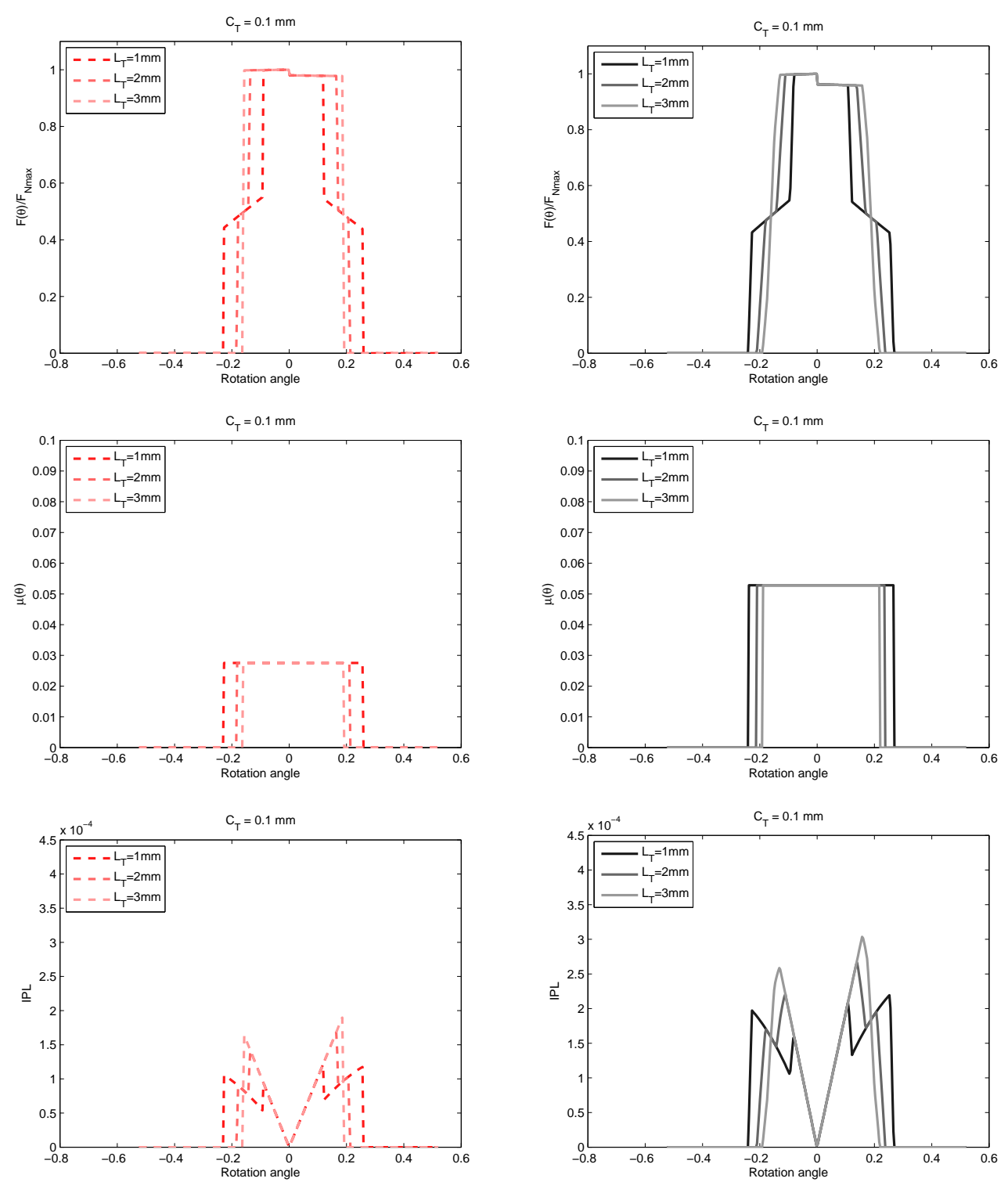

Figure 12: Effect of the tip relief length variation, in the maximum magnitude case, on $L S, F C$ and $I P L$ factor 
In the maximum magnitude case, the contact reduction in both directions is appreciated when the tip relief length increases in the two operating conditions. This contact reduction results in a power loss decrement in both $F D C R$ and $S D C R$, which is higher than the power loss increment in the $S C R$, achieving an improvement of the efficiency with the tip relief length increment.

\section{Study II: Torque analysis in a transmission with long tip relief}

The torque effect on the efficiency of a transmission with long tip relief, which schema can be observed in Figure 13, was analysed in this study.

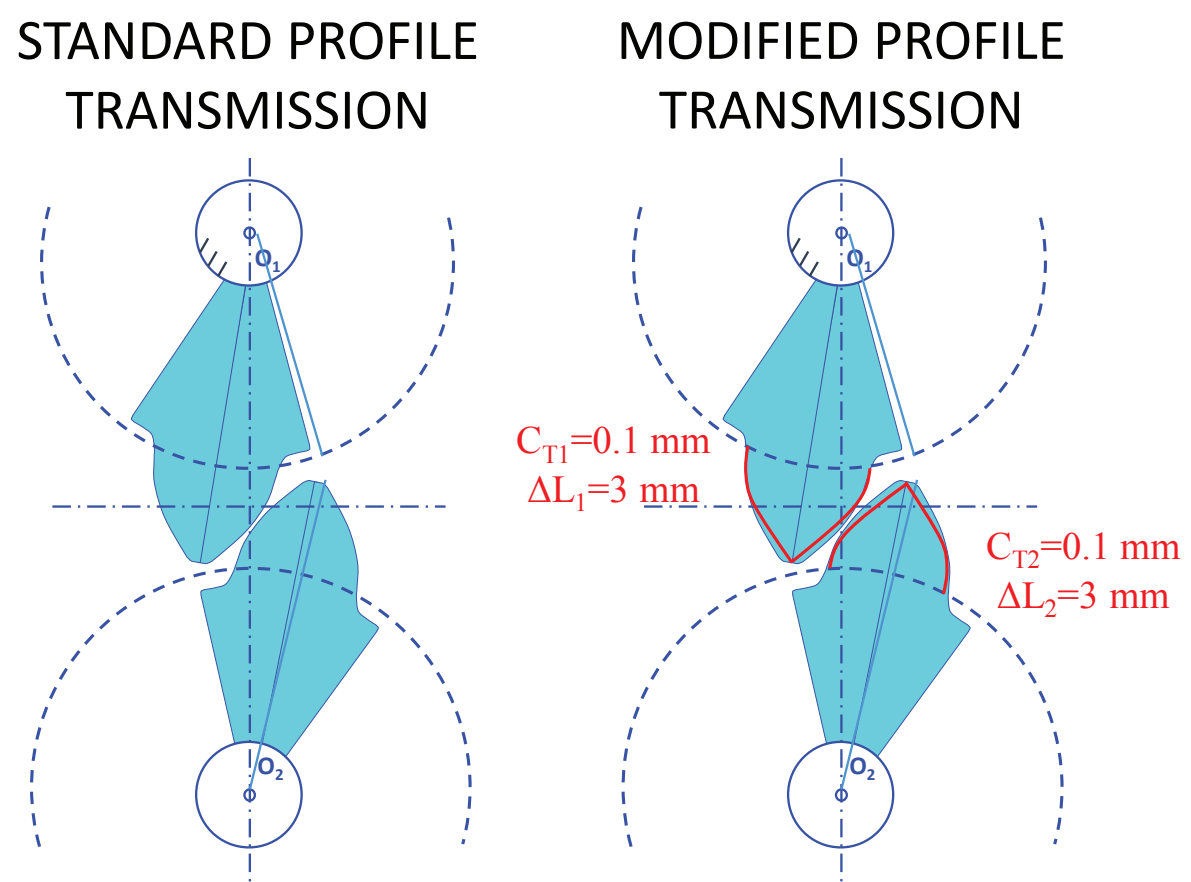

Figure 13: Schema of the transmission with long tip relief

In order to perform this torque analysis, Figure 14 shows the efficiency of this transmission with modified and standard profile. 


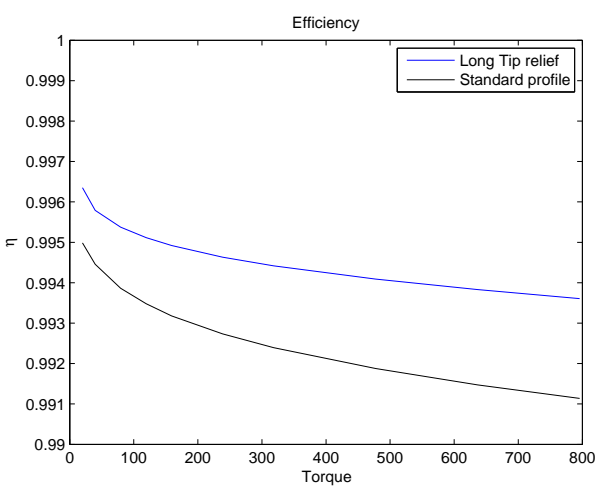

Figure 14: Efficiency of the transmission with long tip relief for different torque levels

From Figure 14, it can be observed that efficiency corresponding to modified profile gives higher results than those related to the standard profile transmission. Moreover, the efficiency tendency with the torque increment is to decrease, no matter the kind of profile. Nevertheless, the decrement is higher in the standard profile case. In order to explain these facts, first the effective contact ratio of each transmission and the theoretical one are presented in Figure 15.

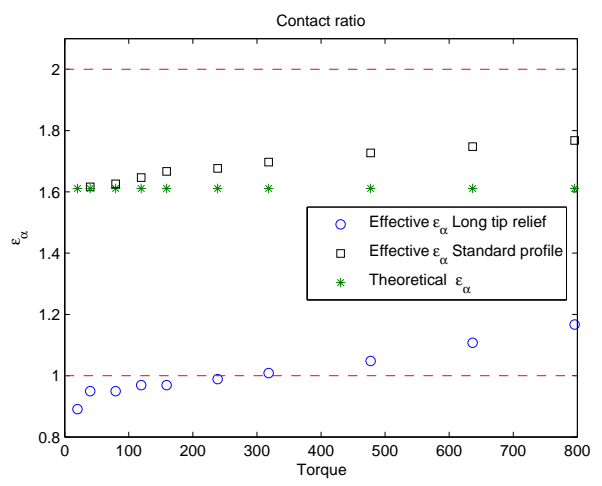

Figure 15: Transmission contact ratio for different torque levels

The effective contact ratio in standard gears is higher than the theoretical and the one corresponding to the transmission with long tip relief. Thus, linking the efficiency and the contact ratio, it can be inferred that the higher the contact ratio, the lower the efficiency is. Moreover, there are some torque levels which make the effective contact ratio of the transmission with tip 
relief lower than one. From the design point of view, it is undesirable that the transmission works in these operating conditions, since impacts occur in the dynamic regime. Hence, this specific tip relief $\left(C_{T_{1}}=C_{T_{2}}=0.1 \mathrm{~mm}\right.$ and $\Delta L_{T_{1}}=\Delta L_{T_{2}}=3 \mathrm{~mm}$ ) makes the efficiency optimal for a torque level of approximately $300 \mathrm{Nm}$ because the effective contact ratio is the unity, even if there are efficiency values higher from the theoretical point of view with lower torques.

Next, the load sharing $(L S)$, friction coefficient $(F C)$ and Instantaneous Power Loss $(I P L)$ factor for both kind of profiles are presented in Figure 16, in order to explain why the efficiency follows the observed trend.

The considered long tip relief produces a high decrement of the contact ratio, which can be appreciated in the three analysed parameters. It can be appreciated that the power losses increase in the single contact region, however, as this region is located in the pitch point area, sliding velocity palliate this increment of power losses. As a matter of fact, the power loss increment in the single-contact area is lower than the power loss reduction in the double-contact regions, turning into an overall reduction of the system power losses.

\section{Conclusions}

In this work, the load sharing impact on the efficiency of spur gears with tip reliefs was assessed. In order to perform it, two different studies were conducted. In the first, the effect of profile modifications on the load sharing and efficiency were done by including several tip reliefs in two specific operating conditions. In the second, the analysis of the torque level on a spur gear transmission with long tip relief was carried out.

From the profile modification assessment, it was observed that tip reliefs produce a reduction in the effective contact ratio, which turns out to increase the efficiency. This effective contact ratio decrement changes its location depending where the tip reliefs are included, as is well known. Pinion tip reliefs resulted in a reduction of the first double-contact region and in an increment of the single-contact region after the pitch point, driven wheel tip reliefs produced a reduction of the second double-contact region and an increment of the single-contact region before the pitch point, whilst, the inclusion of tip reliefs in both gears turned into the superposition of the commented effects. These facts resulted in that the highest efficiency was obtained when 

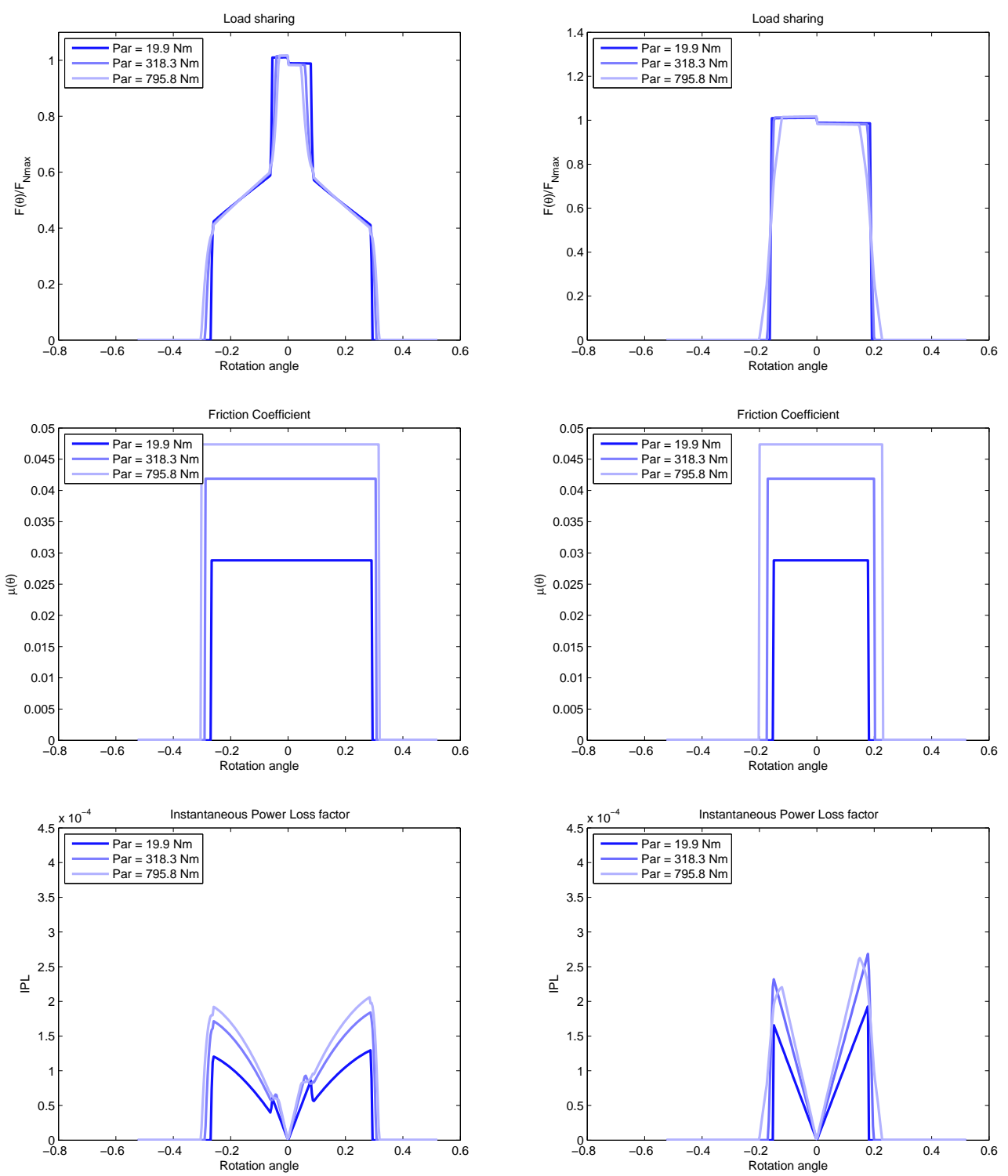

Figure 16: $L S, F C$ and $I P L$ factor of the transmission with long tip relief (on the right) and with standard profile (on the left) for different torque levels

tip reliefs were included to both gears, being the lowest efficiency, the value corresponding to the driven wheel tip reliefs.

From the operating conditions analysis, the higher the torque, the higher 
the contact ratio was, resulting in a decrement of the transmission efficiency. Moreover, from the design point of view, there was a tip relief which makes optimal the efficiency in specific operating conditions. As a matter of interest, in order to obtain this optimal, it is compulsory to take into account the deflections due to the torque levels. This optimal of efficiency corresponds to the unit value of the effective contact ratio, which coincides with the tip relief which theoretically makes optimal the dynamic behaviour (avoiding impacts and changes in the mesh stiffness).

This work is envisaged to be extended to other friction coefficient formulations, which are theoretically closer to the real behaviour, in order to obtain more accurate efficiency results, as well as their experimental validation in later stages.

Acknowledgments The authors would like to acknowledge Project DPI 2013-44860 funded by the Spanish Ministry of Science and Technology and the COST ACTION TU 1105 for supporting this research.

\section{References}

[1] N. E. Anderson and S. H. Loewenthal. Spur-gear-system efficiency at part and full load. NASA Technical Paper, (1622), 1980.

[2] S. Baglioni, F. Cianetti, and L. Landi. Influence of the addendum modification on spur gear efficiency. Mechanism and Machine Theory, 49:216$233,2012$.

[3] G. Bonori, M. Barbieri, and F. Pellicano. Optimum profile modifications of spur gears by means of genetic algorithms. Journal of Sound and Vibration, 313(3-5):603-616, 2008.

[4] L. Chang, Y.-R. Jeng, and P.-Y. Huang. Modeling and analysis of the meshing losses of involute spur gears in high-speed and high-load conditions. Journal of Tribology, 135(1), 2013.

[5] Z. Chen and Y. Shao. Mesh stiffness calculation of a spur gear pair with tooth profile modification and tooth root crack. Mechanism and Machine Theory, 62:63 - 74, 2013.

[6] Y. Diab, F. Ville, and P. Velex. Prediction of power losses due to tooth friction in gears. Tribology Transactions, 49(2):266-276, 2006. 
[7] A. Diez-Ibarbia, A.F. del Rincon, M. Iglesias, A. de Juan, P. Garcia, and F. Viadero. Efficiency analysis of spur gears with a shifting profile. Meccanica, 51(3):707-723, 2016.

[8] C. Fernandes, P. Marques, R. Martins, and J. Seabra. Gearbox power loss. part ii: Friction losses in gears. Tribology International, 88:309 $316,2015$.

[9] A. Fernández del Rincón, M. Iglesias, A. De-Juan, P. García, R. Sancibrián, and F. Viadero. Gear transmission dynamic: Effects of tooth profile deviations and support flexibility. Applied Acoustics, 77(0):138149, 32014.

[10] A. Fernández del Rincón, F. Viadero, M. Iglesias, A. De-Juan, P. García, and R. Sancibrian. Effect of cracks and pitting defects on gear meshing. Proc IMechE Part C: J Mechanical Engineering Science, 226(11):28052815, 2012.

[11] A. Fernández Del Rincón, F. Viadero, M. Iglesias, P. García, A. DeJuan, and R. Sancibrian. A model for the study of meshing stiffness in spur gear transmissions. Mechanism and Machine Theory, 61:30-58, 2013.

[12] S. He, R. Gunda, and R. Singh. Effect of sliding friction on the dynamics of spur gear pair with realistic time-varying stiffness. Journal of Sound and Vibration, 301(3-5):927 - 949, 2007.

[13] B. R Höhn. Improvements on noise reduction and efficiency of gears. Meccanica, 45(3):425-437, 2010.

[14] A. Kahraman and G.W. Blankenship. Effect of involute tip relief on dynamic response of spur gear pairs. Journal of Mechanical Design, Transactions of the ASME, 121(2):313-315, 1999.

[15] S. Li. Effects of machining errors, assembly errors and tooth modifications on loading capacity, load-sharing ratio and transmission error of a pair of spur gears. Mechanism and Machine Theory, 42(6):698 - 726, 2007. 
[16] S. Li. Finite element analyses for contact strength and bending strength of a pair of spur gears with machining errors, assembly errors and tooth modifications. Mechanism and Machine Theory, 42(1):88 - 114, 2007.

[17] S. Li and A. Kahraman. Prediction of spur gear mechanical power losses using a transient elastohydrodynamic lubrication model. Tribology Transactions, 53(4):554-563, 2010.

[18] H.S. Lin, F.B. Oswald, and D.P. Townsend. Dynamic loading of spur gears with linear or parabolic tooth profile modifications. Mechanism and Machine Theory, 29(8):1115-1129, 1994.

[19] G. Liu and R.G. Parker. Dynamic modeling and analysis of tooth profile modification for multimesh gear vibration. Journal of Mechanical Design, Transactions of the ASME, 130(12):1214021-12140213, 2008.

[20] H. Ma, J. Zeng, R. Feng, X. Pang, and B. Wen. An improved analytical method for mesh stiffness calculation of spur gears with tip relief. Mechanism and Machine Theory, 98:64 - 80, 2016.

[21] L. Magalhes, R. Martins, C. Locateli, and J. Seabra. Influence of tooth profile and oil formulation on gear power loss. Tribology International, 43(10):1861-1871, 2010.

[22] K. Marković and Ž. Vrcan. Influence of tip relief profile modification on involute spur gear stress. Transactions of Famena, 40(2):59-70, 2016.

[23] P. Marques, R. Martins, and J. Seabra. Power loss and load distribution models including frictional effects for spur and helical gears. Mechanism and Machine Theory, 96:1-25, 2016.

[24] P.M.T. Marques, R. Camacho, R.C. Martins, and J.H.O. Seabra. Efficiency of a planetary multiplier gearbox: Influence of operating conditions and gear oil formulation. Tribology International, 92:272-280, 2015.

[25] K. Michaelis, B. R Höhn, and M. Hinterstoißer. Influence factors on gearbox power loss. Industrial Lubrication and Tribology, 63(1):46-55, 2011. 
[26] M. Mohammadpour, S. Theodossiades, H. Rahnejat, and P. Kell. Transmission efficiency and noise, vibration and harshness refinement of differential hypoid gear pairs. Proceedings of the Institution of Mechanical Engineers, Part K: Journal of Multi-body Dynamics, 228(1):19-33, 2014.

[27] G. Niemann and J. Baethgei. Transmission error, tooth stiffness, and noise of parallel axis gears. VDI-Z, 2(4), 1970.

[28] Official Journal of the European Communities. Commission regulation (EC) No 692/2008 of 18 July 2008 implementing and amending regulation (EC) No 715/2007 of the european parliament and of the council on type-approval of motor vehicles with respect to emissions from light passenger and commercial vehicles (euro 5 and euro 6) and on access to vehicle repair and maintenance information (1). Official Journal of the European Communities, 2008.

[29] H. Ohlendorf. Verlustleistung und erwärmung von stirnrädern, 1958.

[30] D. Palmer and M. Fish. Evaluation of methods for calculating effects of tip relief on transmission error, noise and stress in loaded spur gears. American Gear Manufacturers Association Fall Technical Meeting 2010, pages 112-126, 2010.

[31] T. T. Petry-Johnson, A. Kahraman, N. E. Anderson, and D. R. Chase. An experimental investigation of spur gear efficiency. Journal of Mechanical Design, Transactions of the ASME, 130(6):0626011-06260110, 2008.

[32] M. Pleguezuelos, J. I. Pedrero, and M. B. Sánchez. Analytical expressions of the efficiency of standard and high contact ratio involute spur gears. Mathematical Problems in Engineering, 2013, 2013.

[33] P. Velex and F. Ville. An analytical approach to tooth friction losses in spur and helical gears-influence of profile modifications. Journal of Mechanical Design, Transactions of the ASME, 131(10):1010081-10100810, 2009. 